\title{
The Interaction of Ethylene with Free Gold Cluster Cations: Infrared Photodissociation Spectroscopy Combined with Electronic and Vibrational Structure Calculations
}

\author{
Sandra M. Lang, ${ }^{1,2 *}$ Thorsten M. Bernhardt, ${ }^{1}$ Joost M. Bakker, ${ }^{3}$ Bokwon Yoon, ${ }^{2}$ Uzi Landman ${ }^{2 *}$ \\ ${ }^{1}$ Institute of Surface Chemistry and Catalysis, University of Ulm, Albert-Einstein-Allee 47, 89069 Ulm, \\ Germany \\ ${ }^{2}$ School of Physics, Georgia Institute of Technology, Atlanta, GA 30332-0430, USA \\ ${ }^{3}$ Radboud University, Institute for Molecules and Materials, FELIX Laboratory, Toernooiveld 7c, 6525 \\ ED Nijmegen, The Netherlands \\ E-mail: sandra.lang@uni-ulm.de, uzi.landman@physics.gatech.edu
}

\begin{abstract}
The interaction of ethylene with free gold clusters of different sizes and charge states has been previously shown theoretically to involve two different adsorption modes of the $\mathrm{C}_{2} \mathrm{H}_{4}$ molecule, namely: the di- $\square$ - and $\square$-bonded ethylene adsorption configurations. Here, we present the first experimental investigation of the structure of a series of gas-phase gold-ethylene complexes, $\mathrm{Au}_{\mathrm{x}}\left(\mathrm{C}_{2} \mathrm{H}_{4}\right)_{\mathrm{y}}{ }^{+}(\mathrm{x}=2-4, \mathrm{y}=1-3)$. By employing infrared multiple-photon dissociation spectroscopy (IR-MPD) in conjunction with first-principles calculations it is uncovered that up to three $\mathrm{C}_{2} \mathrm{H}_{4}$ molecules bind to gold cations exclusively in a $\square$-bonded configuration. The binding of all ethylene molecules is found to be dominated by partial electron donation from the ethylene molecules to the gold clusters leading to an activation of the $\mathrm{C}-\mathrm{C}$ bond. The cooperative action of multiple coadsorbed $\mathrm{C}_{2} \mathrm{H}_{4}$ on $\mathrm{Au}_{4}{ }^{+}$is shown to enable additional charge back-donation and an enhanced $\mathrm{C}$-C bond activation. In contrast, the strong $\mathrm{C}-\mathrm{H}$ bond is not weakened and the experimental spectra do not give any indication for $\mathrm{C}-\mathrm{H}$ bond dissociation. The possible correlations of the $\mathrm{C}-\mathrm{C}$ bond stretch vibration with the $\mathrm{C}-\mathrm{C}$ bond length and the net charge transfer are discussed.
\end{abstract}

Keywords: gold, ethylene, infrared multiple photon dissociation spectroscopy, density functional calculations

\section{Introduction}

Ethylene, $\mathrm{C}_{2} \mathrm{H}_{4}$, is one of the most important molecules for the petrochemical industry since it represents the precursor material for the production of e.g. polyethylene (and thus plastics), acetaldehyde, ethylene oxide, and many other venerable materials [1-4]. All these processes require the presence of a suitable catalyst which promotes the conversion of ethylene.

To enable the useful exploitation of the above-mentioned oxidation reactions it is not sufficient to find a catalyst which will only promote the efficiency of the ethylene conversion. Instead, it is imperative that the chosen catalyst will promote in a highly selective manner the partial oxidation to the oxide or epoxide species, but not the full oxidation to $\mathrm{CO}_{2}$ and water [2]. A promising candidate for such a selective oxidation catalyst is nano-sized or even subnano-sized gold. Subsequent to the work of Haruta [5] in the 1980's, numerous studies demonstrated the ability of small gold particles as low temperature oxidation catalysts, e.g. for the oxidation of $\mathrm{CO}$, propylene, and formaldehyde, or ethylene (see e.g. [6-12] and references therein).

The first step in any ethylene converting catalytic reaction is the interaction of ethylene with the catalyst which either leads to the activation of the strong $\mathrm{C}=\mathrm{C}$ double bond (733 \pm $8 \mathrm{~kJ} / \mathrm{mol}$ [13]) or the strong C-H bond (465 $\pm 3 \mathrm{~kJ} / \mathrm{mol}$ [13]) of $\mathrm{C}_{2} \mathrm{H}_{4}$ and thus prepares the molecule for further reactions. Thus, the investigation of this elementary reaction step is 
essential for the understanding of all subsequent catalytic reactions involving ethylene.

On gold (similar to other transition metals) ethylene typically adsorbs in one of two different configurations, a $\square$ bonded configuration with both carbon atoms coordinating to the same Au atom or a di- $\square$-bonded configuration with the $\mathrm{C}$ atoms bridging two neighboring $\mathrm{Au}$ atoms. In the $\square$-bonded configuration the $\mathrm{C}$ atoms retain their $\mathrm{sp}^{2}$ hybridization of the free $\mathrm{C}_{2} \mathrm{H}_{4}$ molecule whereas they are re-hybridized to an almost $\mathrm{sp}^{3}$-like state in the di- $\square$-bonded configuration. Thus, the di- $\square$-bonded configuration typically leads to a stronger activation and elongation of the $\mathrm{C}-\mathrm{C}$ bond (compare the $\mathrm{C}=\mathrm{C}$ bond length $d(\mathrm{C}=\mathrm{C})=1.339 \AA$ in free $\mathrm{C}_{2} \mathrm{H}_{4}$ with $\mathrm{sp}^{2}$ hybridization to $d(\mathrm{C}-\mathrm{C})=1.535 \AA$ in free $\mathrm{C}_{2} \mathrm{H}_{6}$ with $\mathrm{sp}^{3}$ hybridzation [13]). Thus, the binding mode determines the degree of ethylene $\mathrm{C}=\mathrm{C}$ bond activation which is important for further (oxidation) reactions.

Using temperature-programmed reaction spectroscopy ethylene has been found to adsorb molecularly on an $\mathrm{Au}(110)$ surface without any indication for dissociation of the molecule [14]. Surface enhanced Raman spectroscopy revealed adsorption in a $\square$-bonded configuration on a cryocondensed gold film under ultra-high vacuum (UHV) conditions at $40 \mathrm{~K}[15,16]$. Such a configuration has also been observed on gold electrodes [17]. In agreement with these experiments, a density functional theory investigation showed that on an $\mathrm{Au}(110)$ surface this configuration is 0.15 $\mathrm{eV}$ more stable (adsorption energy of $0.44 \mathrm{eV}$ ) than the di- $\square$ bonded configuration $(0.29 \mathrm{eV})$ [18], whereas only very weak interaction, of $0.08 \mathrm{eV}$, between $\mathrm{C}_{2} \mathrm{H}_{4}$ and an $\mathrm{Au}(111)$ surface has been observed [19]. Furthermore, some theoretical studies employing clusters as structural models for gold surfaces have been reported. $\mathrm{Au}_{25}$ and $\mathrm{Au}_{32}$, serving as models for $\mathrm{Au}(111)$ and $\mathrm{Au}(100)$ surfaces, respectively, were found to adsorb ethylene in a di- $\square$-bonded configuration [20], whereas $\mathrm{Au}_{38}$ adsorbs $\mathrm{C}_{2} \mathrm{H}_{4}$ in a di- $\square-$ bonded configuration on an fcc(100) surface but in a $\square$ bonded configuration on an fcc(111) surface [21]. Additionally, it was shown that $\mathrm{C}_{2} \mathrm{H}_{4}$ prefers to bind to corner $\mathrm{Au}$ atoms in $\mathrm{Au}_{79}$ and $\mathrm{Au}_{140}$ in a $\square$-bonded configuration $[22,23]$. Similarly, both $\square$ - and di- $\square$-bonded species were observed on a $0.7 \mathrm{~nm}$ gold particle deposited on $\mathrm{Al}_{2} \mathrm{O}_{3}$ at $300 \mathrm{~K}$ and $373 \mathrm{~K}$ [24]. Infrared spectroscopy on mononuclear gold complexes supported on $\mathrm{MgO}$ powder were found to adsorb ethylene in a $\square$-bonded configuration at atmospheric pressure up to $353 \mathrm{~K}$ [25].

Several theoretical studies on the interaction between ethylene and small free gold clusters have been reported. For over a decade, free clusters have been shown to represent suitable and versatile model systems to mimic the catalytically active sites of heterogeneous catalysts [26-30]. These studies revealed that small neutral and anionic gold clusters preferably bind ethylene in a $\square$-like configuration with the exception of the neutral $\mathrm{Au}$ atom and the $\mathrm{Au}_{5}$ cluster [31-35]. The only systematic study on cationic clusters $\left(\mathrm{Au}_{\mathrm{x}}{ }^{+}, \mathrm{x}=1-10\right)$ was reported by Lyalin and Taketsugu showing the preferred adsorption of one $\mathrm{C}_{2} \mathrm{H}_{4}$ molecule in a $\square$-bonded configuration [31]. However, the di- $\square$-bonded isomers are typically (with a few exceptions) less than $0.5 \mathrm{eV}$ less stable. For $\mathrm{Au}_{10}\left(\mathrm{C}_{2} \mathrm{H}_{4}\right)^{+}$it has been shown that this configuration is independent of the dimensionality of the cluster [34]. The only study considering the adsorption of multiple ethylene molecules on a gold cation reported that up to three $\mathrm{C}_{2} \mathrm{H}_{4}$ molecules are adsorbed on $\mathrm{Au}_{3}{ }^{+}$in a $\square$-bonded configuration [36]. The predicted binding energies between $\mathrm{Au}_{3}{ }^{+}$and up to three $\mathrm{C}_{2} \mathrm{H}_{4}$ molecules are consistent with experimental values [37]. Bowers and coworkers experimentally determined the bond strength of up to seven ethane molecules on $\mathrm{Au}_{\mathrm{x}}{ }^{+}(\mathrm{x}=1,3-9)$ and showed a rather strong binding of multiple $\mathrm{C}_{2} \mathrm{H}_{4}$ molecules. Only after occupation of all accessible $\mathrm{Au}$ atoms in the cluster further $\mathrm{C}_{2} \mathrm{H}_{4}$ bind considerably weaker [37]. Notably, none of these experimental and theoretical studies on gold surfaces and clusters indicate the decomposition of ethylene to e.g. ethylidyne as has for example been reported to occur on platinum extended surfaces [38, 39] and supported Pt clusters [24, 40, 41].

Hence, experimental investigations of the interaction between ethylene and gold are scarce and most studies have been entirely theoretical. In particular, to-date no experimental study of complexes formed on free gold clusters has been reported, except from a reaction study focusing on the bond strength of multiple adsorbed molecules [37] and an early spectroscopic study in the infrared as well visible and ultraviolet wavelength region of co-condensed $\mathrm{Au}$ atoms and $\mathrm{C}_{2} \mathrm{H}_{4}$ [42]. In the latter study, several bands have been observed in the spectra, but no final conclusion on the $\mathrm{C}_{2} \mathrm{H}_{4}$ binding mode could be drawn. Since several theoretical studies have shown that the $\square$ - and di- $\square$ bonded configurations are often close in energy, i.e. both might be accessible at room temperature, further experimental investigations are essential to shed light on the adsorption configuration and the potential of gold clusters to bind ethylene in different isomeric configurations at room temperature and below.

Towards this goal, we present here the first experimental study of the interaction between ethylene and free cationic gold clusters. Since the binding configuration strongly affects the hybridization of the $\mathrm{C}$ atoms $\left(\mathrm{sp}^{3}\right.$-like hybridization for $\square$-bonded and $\mathrm{sp}^{2}$-like hybridization for di$\square$-bonded configuration) and thus the $\mathrm{C}$ - $\mathrm{C}$ bond length, vibrational spectroscopy offers a versatile method for gaining fundamental insight into the bonding configuration. Consequently, we employed infrared multiple-photon dissociation spectroscopy (IR-MPD) in conjunction with first-principles calculations to investigate the structure of a 
series of $\mathrm{Au}_{\mathrm{x}}\left(\mathrm{C}_{2} \mathrm{H}_{4}\right)_{\mathrm{y}}^{+}(\mathrm{x}=2-4, \quad \mathrm{y}=1-3)$ complexes. In particular, we show that up to three $\mathrm{C}_{2} \mathrm{H}_{4}$ molecules bind to gold cations exclusively in a $\square$-bonded configuration, leading to activation of the $\mathrm{C}=\mathrm{C}$ double bond, whereas the $\mathrm{C}$ $\mathrm{H}$ bond is almost unaffected. The nature of the gold-ethylene interaction as well as possible correlations of the $\mathrm{C}-\mathrm{C}$ bond stretch vibrational frequency with the $\mathrm{C}-\mathrm{C}$ bond length and the net charge transfer are discussed on the basis of theoretical simulations.

\section{Methods}

\subsection{Experimental Methods}

Cationic gold clusters were produced by pulsed laser ablation of a rotating gold target using the second harmonic of a Nd:YAG laser. The ablation took place in a $3 \mathrm{~mm}$ diameter and $60 \mathrm{~mm}$ long growth channel in the presence of a short pulse of helium carrier gas. To enhance cluster growth the He buffer gas was seeded with about $5 \%$ oxygen; while this also led to the formation of $\mathrm{Au}_{\mathrm{x}} \mathrm{O}_{2}{ }^{+}$complexes, these do not interfere due to the mass-selective detection method. Clusterethylene complexes were formed by introducing a mixture of $1 \%$ ethylene in helium via a second pulsed valve $50 \mathrm{~mm}$ downstream in a flow tube reactor. The gold cluster/ethylene reaction resulted in the formation of $\mathrm{Au}_{\mathrm{x}}\left(\mathrm{C}_{2} \mathrm{H}_{4}\right)_{\mathrm{y}}{ }^{+}(\mathrm{x}=2-4$ and $\mathrm{y}=1-2)$ without any indication of ethylene dehydrogenation in the mass spectrometric analysis.

On exiting the flow reactor, the reaction mixture was expanded into vacuum forming a molecular beam, which was collimated by a $2-\mathrm{mm}$ diameter skimmer and a $8 \times 0.45 \mathrm{~mm}$ horizontal slit aperture. After shaping, the ion beam entered the intracavity region where it interacted with the IR laser beam of the Free Electron Laser for Intra Cavity Experiments (FELICE) crossing it in the horizontal plane at an angle of $35^{\circ}$.

FELICE laser pulses are produced in a pulse train, the socalled macropulse, with a typical duration of $9 \mu \mathrm{s}$, consisting of ps-long micropulses at a 1 ns separation. The near transform limited radiation of FELICE covered the 200-1800 $\mathrm{cm}^{-1}$ spectral range and the spectral width was set to approximately $0.4 \%$ FWHM of the central frequency.

A few $\mu$ s after interaction with FELICE, all clusters were extracted by a set of pulsed high voltage plates into a reflectron time-of-flight mass spectrometer and detected with a microchannel plate detector [43, 44].

Whenever the IR laser was in resonance with an IR active vibrational mode of a given cluster complex, multiple IR photons were absorbed sequentially. This led to a heating of the complexes and, when the internal energy was sufficient, to their fragmentation, resulting in a depletion of the number detected. Infrared multiple photon dissociation (IR-MPD) spectra were recorded by measuring the cluster-complex intensity $(I)$ in the mass spectrum as a function of the IR frequency. To correct for long term source fluctuations, the experiment was operated at twice the FELICE repetition rate, allowing for the recording of reference mass spectra $\left(I_{0}\right)$ in between successive FELICE pulses. As a consequence of the required absorption of multiple photons, this technique to record vibrational spectra the observed IR intensities can generally deviate from the linear IR absorption, as predicted by calculations [45].

\subsection{Theoretical Methods}

The theoretical explorations of the atomic arrangements and electronic structures of the gold clusters and their complexes were performed with the use of density-functional theory (DFT) employing the Vienna ab initio simulation package VASP [46-49]. The wavefunctions were expanded in a plane wave basis with a kinetic energy cut-off of $400 \mathrm{eV}$. The interaction between the atom cores and the valence electrons was described by the projector augmented-wave (PAW) potential [50] and the exchange-correlation potential was described by the PBE generalized gradient approximation (GGA) [51].

For all calculations, a supercell with a lattice constant of $25 \AA$ was used to avoid any interactions between the cluster complexes and their periodic images. To further minimize the electrostatic interaction with the images a neutralizing background charge as well as dipole and quadrupole corrections to the total energy were applied [52]. For structure optimization, convergence was achieved when the change in the total free energy was smaller than $10^{-6} \mathrm{eV}$.

The wavefunction character was evaluated by projecting the wave functions onto spherical harmonics (in particular $1=$ $0,1,2)$ within spheres around each atom (angular-momentum projected local density of states, PLDOS). The radius of the spheres was chosen as the half of the average bond length (covalent radius) and amounted to $1.36 \AA$ ( $\mathrm{Au}), 0.76 \AA$ (C), and $0.31 \AA(\mathrm{H})$ [53]. The DOS shown in this contribution (see Figure 2) for the entire cluster complexes (gray shaded) and the $\mathrm{C}_{2} \mathrm{H}_{4}$ molecule (green shaded) is the sum of the projected contributions $(1=0-2)$ calculated for each of the involved atoms.

To obtain insight into the charge transfer upon complex formation the charge density difference between the complex $\square\left[\mathrm{Au}_{\mathrm{x}}\left(\mathrm{C}_{2} \mathrm{H}_{4}\right)_{\mathrm{y}}{ }^{+}\right]$and the individual components, $\square\left[\mathrm{Au}_{\mathrm{x}}{ }^{+}\right]$and $\square\left[\mathrm{y} \quad\left(\mathrm{C}_{2} \mathrm{H}_{4}\right)\right]$, was calculated according to $\square \square \square=$ $\square\left[\mathrm{Au}_{\mathrm{x}}\left(\mathrm{C}_{2} \mathrm{H}_{4}\right)_{\mathrm{y}}{ }^{+}\right]-\square\left[\mathrm{Au}_{\mathrm{x}}^{+}\right]-\square\left[\mathrm{y}\left(\mathrm{C}_{2} \mathrm{H}_{4}\right)\right]$. The net charge transfer from $\mathrm{C}_{2} \mathrm{H}_{4}$ to the gold cluster was then estimated from $\square \square$ by attributing the charge on each grid point to the nearest atom and summing over all these charges.

The vibrational spectra of the cluster complexes were calculated in the harmonic approximation by dermining the dynamical matrix (matrix containing the electron density response to atomic displacements from equilibrium) using density functional perturbation theory $[54,55]$. 


\section{Results and Discussion}

\subsection{IR-MPD Spectra of $\mathrm{Au}_{2}\left(\mathrm{C}_{2} \mathrm{H}_{4}\right)_{y}{ }^{+}$}

Previous theoretical investigations of $\mathrm{Au}_{x}\left(\mathrm{C}_{2} \mathrm{H}_{4}\right)_{y}$ complexes of different size and charge state demonstrated that $\mathrm{C}_{2} \mathrm{H}_{4}$ can be adsorbed on small free gold clusters in two different configurations [31-36, 56]. In the so-called $\square$-bonded configuration, both carbon atoms of $\mathrm{C}_{2} \mathrm{H}_{4}$ coordinate to the same $\mathrm{Au}$ atom and the $\mathrm{C}$ atoms approximately retain the $\mathrm{sp}^{2}$ hybridization of the free $\mathrm{C}_{2} \mathrm{H}_{4}$ molecule. In contrast, in the di- $\square$-bonded configuration, $\mathrm{C}_{2} \mathrm{H}_{4}$ bridges two $\mathrm{Au}$ atoms via coordination of each $\mathrm{C}$ atom to a different $\mathrm{Au}$ atom. This leads to a considerable rearrangement of the ethylene electronic structure and nearly $\mathrm{sp}^{3}$ hybridized carbon atoms.

Since the C-C stretch frequency of free $\mathrm{C}_{2} \mathrm{H}_{4}$ is highly sensitive to the hybridization state of the carbon atoms (compare $995 \mathrm{~cm}^{-1}$ for $\mathrm{C}_{2} \mathrm{H}_{6}, 1623 \mathrm{~cm}^{-1}$ for $\mathrm{C}_{2} \mathrm{H}_{4}$, and $1974 \mathrm{~cm}^{-1}$ for $\mathrm{C}_{2} \mathrm{H}_{2}$ which represent $\mathrm{sp}^{3}, \mathrm{sp}^{2}$, and $\mathrm{sp}$ hybridized molecules, respectively [57]) it has been proposed that the two adsorption configurations in isolated $\mathrm{Au}_{\mathrm{x}}\left(\mathrm{C}_{2} \mathrm{H}_{4}\right)_{\mathrm{y}}$ can be distinguished on the basis of the $\mathrm{C}-\mathrm{C}$ stretch mode in the vibrational spectra [31-33]. However, the $\mathrm{C}-\mathrm{C}$ stretch mode of $\mathrm{C}_{2} \mathrm{H}_{4}$ is strongly coupled with the in-plane $\mathrm{CH}_{2}$ scissor mode leading to two mixed vibrational modes which correspond to frequencies of 1623 and $1342 \mathrm{~cm}^{-1}$ in the free $\mathrm{C}_{2} \mathrm{H}_{4}$ molecule [57] (compare to the theoretically values of $1639 \mathrm{~cm}^{-1}$ and $1341 \mathrm{~cm}^{-1}$ calculated in this study). Thus, both modes appear to be characteristic for the hybridization state and will be considered in the following discussion of the experimental vibrational spectra.

Figure 1 displays the IR-MPD spectra recorded on the mass signals corresponding to $\mathrm{Au}_{2}\left(\mathrm{C}_{2} \mathrm{H}_{4}\right)^{+}$(labeled 2,1) and $\mathrm{Au}_{2}\left(\mathrm{C}_{2} \mathrm{H}_{4}\right)_{2}{ }^{+}$(labeled 2,2) in the wavenumber range of 500 $1750 \mathrm{~cm}^{-1}$, respectively, as well as calculated vibrational spectra of three isomeric structures each (iso 2,1-a to iso 2,1$\mathrm{c}$ as well as iso 2,2-a to iso 2,2-c). The experimental spectra show the ratio of the mass peak intensity obtained with $(I)$ and without $\left(I_{0}\right)$ laser light. When the light is not resonant with a vibrational transition, no fragmentation occurs and the ratio $I / I_{0}$ is 1 . In case of resonant absorption of IR light the cluster complex fragments and the ratio $I / I_{0}$ becomes smaller than 1 which appears as a 'depletion' in the IR-MPD

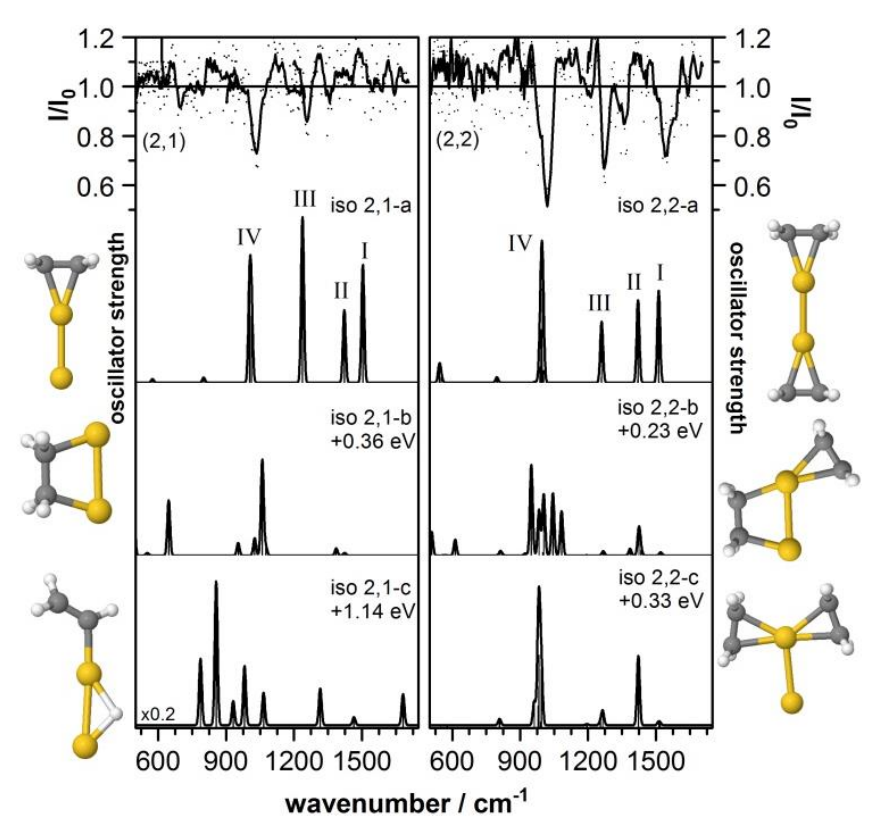

Figure 1: Top: IR-MPD spectra of $\mathrm{Au}_{2}\left(\mathrm{C}_{2} \mathrm{H}_{4}\right)^{+}$(left column) and $\mathrm{Au}_{2}\left(\mathrm{C}_{2} \mathrm{H}_{4}\right)_{2}{ }^{+}$(right column). The dots represent the average of typically five spectra and the solid lines are a five point adjacentaverage smoothing. Other panels: Cyalculated vibrational spectra of different structural isomers, presented as oscillator strengths (sticks) and as convoluted with a $20 \mathrm{~cm}^{-1}$ FWHM Gaussian line shape function. Structural models: Yellow, gray and white spheres represent $\mathrm{Au}, \mathrm{C}$ and $\mathrm{H}$ atoms, respectively.

spectrum. At the same time a larger cluster may fragment into the mass channel of a specific cluster complex, causing an intensity 'gain', which is reflected by a $I / I_{0}$ value larger than 1 .

The experimental spectrum of $\mathrm{Au}_{2}\left(\mathrm{C}_{2} \mathrm{H}_{4}\right)^{+}$shows two features at $1261 \mathrm{~cm}^{-1}$ and $1031 \mathrm{~cm}^{-1}$ whereas the spectrum of $\mathrm{Au}_{2}\left(\mathrm{C}_{2} \mathrm{H}_{4}\right)_{2}{ }^{+}$shows four depletion bands at 1549, 1355, 1279, and $1016 \mathrm{~cm}^{-1}$. The minimum energy structure of $\mathrm{Au}_{2}\left(\mathrm{C}_{2} \mathrm{H}_{4}\right)^{+}$ (iso 2,1-a) corresponds to the $\square$-bonded configuration with a $\mathrm{C}_{2} \mathrm{H}_{4}$ binding energy of $2.34 \mathrm{eV}$, while the di- $\square$-bonding configuration (iso 2,1-b) is $0.36 \mathrm{eV}$ higher in energy. The experimentally observed bands are very well represented by the modes labeled III and IV of iso 2,1-a which correspond to one of the mixed $\mathrm{C}-\mathrm{C}$ stretch/ $\mathrm{CH}_{2}$ scissor motions of $\mathrm{C}_{2} \mathrm{H}_{4}$ (band III) as well as to $\mathrm{CH}_{2}$ wagging modes (band IV). Although the experimentally observed mode at $1031 \mathrm{~cm}^{-1}$ can also be described by a mode of the di- $\square$-bonded isomer iso 2,1-b, the mode at $1261 \mathrm{~cm}^{-1}$ is clearly not reproduced by this isomer. Due to the di- $\square$-bonding this combined C-C stretch $/ \mathrm{CH}_{2}$ scissor mode is highly red-shifted to $1026 \mathrm{~cm}^{-1}$ and the oscillator strength is reduced by a factor of 10 . As a consequence, we assign the spectrum to iso 2,1-a. Bands I and II are not clearly visible in the experiment, but they are predicted at frequencies where $\mathrm{Au}_{2}\left(\mathrm{C}_{2} \mathrm{H}_{4}\right)_{2}{ }^{+}$shows fragmentation; a hint of a potential band at $1200 \mathrm{~cm}^{-1}$ is discernible. 
The minimum energy structure of $\mathrm{Au}_{2}\left(\mathrm{C}_{2} \mathrm{H}_{4}\right)_{2}{ }^{+}$ corresponds to a complex with one $\mathrm{C}_{2} \mathrm{H}_{4}$ adsorbed on each $\mathrm{Au}$ atom in a $\square$-bonded configuration (iso 2,2-a, with an average $\mathrm{C}_{2} \mathrm{H}_{4}$ binding energy of $2.00 \mathrm{eV}$ ). Isomers with one and two di- $\square$-bonded $\mathrm{C}_{2} \mathrm{H}_{4}$ molecules are $0.23 \mathrm{eV}$ (iso 2,2-b) and $0.67 \mathrm{eV}$ (iso 2,2-d) higher in energy, while the isomer with both $\mathrm{C}_{2} \mathrm{H}_{4} \square$-bonded to the same $\mathrm{Au}$ atom (iso 2,2-c) is $0.33 \mathrm{eV}$ higher in energy. The spectrum of the minimum energy isomer is in favorable agreement with the IR-MPD spectrum and all four experimental signals are nicely mirrored in the calculated spectrum. The bands can be assigned to mixed C-C stretch/ $\mathrm{CH}_{2}$ scissor motions of $\mathrm{C}_{2} \mathrm{H}_{4}$ (bands I and III), $\mathrm{CH}_{2}$ scissor motions (band II), and $\mathrm{CH}_{2}$ wagging motions (band IV). Also the spectrum of the $\square$ bonded iso 2,2-c is in agreement with the IR-MPD spectrum (cf. Figure 1) and cannot be distinguished from iso 2,2-a. In marked contrast, the existence of the other two higher energy isomers containing at least one di- $\square$-bonded ethylene molecule can be excluded based on their spectra. Isomer 2,2b should lead to a considerably broadened peak around 1100 $\mathrm{cm}^{-1}$ (cf. Figure 1) and isomer 2,2-d should result in a double peak around $900 \mathrm{~cm}^{-1}$ (cf. Figure S1). Furthermore, for iso 2,2-d the mode around $950 \mathrm{~cm}^{-1}$ is noticeably shifted compared to the experimental spectrum and the mode at around $1150 \mathrm{~cm}^{-1}$ is absent in the experimental spectrum at all.

Furthermore, we note that the theoretically predicted bands I and II of iso 2,1-a are not observed in the experimental spectrum of $\mathrm{Au}_{2}\left(\mathrm{C}_{2} \mathrm{H}_{4}\right)^{+}$which we interpret to be caused by an overlap of a depletion and a gain signal. Both $\mathrm{Au}_{2}\left(\mathrm{C}_{2} \mathrm{H}_{4}\right)^{+}$and $\mathrm{Au}_{2}\left(\mathrm{C}_{2} \mathrm{H}_{4}\right)_{2}{ }^{+}$absorb light and fragment via loss of $\mathrm{C}_{2} \mathrm{H}_{4}$, as given in the following:

$\mathrm{Au}_{2}\left(\mathrm{C}_{2} \mathrm{H}_{4}\right)^{+} \rightarrow \mathrm{Au}_{2}^{+}+\mathrm{C}_{2} \mathrm{H}_{4}$,

$\mathrm{Au}_{2}\left(\mathrm{C}_{2} \mathrm{H}_{4}\right)_{2}{ }^{+} \rightarrow \mathrm{Au}_{2}\left(\mathrm{C}_{2} \mathrm{H}_{4}\right)^{+}+\mathrm{C}_{2} \mathrm{H}_{4}$.

Thus, $\mathrm{Au}_{2}\left(\mathrm{C}_{2} \mathrm{H}_{4}\right)^{+}$can serve as both the source and the product of a fragmentation process. Depending on the relative signal intensities of the two cluster complexes as well as the oscillator strength of the vibrational modes this can lead to a cancellation of the depletion and gain signals and thus to $I / I_{0}=1$ in the IR spectrum (i.e. the modes are not detectable in our data). A comparison of the calculated spectra of iso 2,1-a and iso 2,2-a nicely explains the missing bands $\mathrm{I}$ and II in the IR-MPD spectrum of $\mathrm{Au}_{2}\left(\mathrm{C}_{2} \mathrm{H}_{4}\right)^{+}$. In the spectral region of bands I and II both complexes have vibrational modes with roughly the same frequency (1504 $\mathrm{cm}^{-1}$ and $1422 \mathrm{~cm}^{-1}$ for $\mathrm{Au}_{2}\left(\mathrm{C}_{2} \mathrm{H}_{4}\right)^{+}$as well as $1512 \mathrm{~cm}^{-1}$ and $1421 \mathrm{~cm}^{-1}$ for $\mathrm{Au}_{2}\left(\mathrm{C}_{2} \mathrm{H}_{4}\right)_{2}{ }^{+}$) which leads to a cancelation in the IR-MPD spectrum of $\mathrm{Au}_{2}\left(\mathrm{C}_{2} \mathrm{H}_{4}\right)^{+}$via fragmentation of $\mathrm{Au}_{2}\left(\mathrm{C}_{2} \mathrm{H}_{4}\right)_{2}{ }^{+}$into the mass channel of $\mathrm{Au}_{2}\left(\mathrm{C}_{2} \mathrm{H}_{4}\right)^{+}$. In contrast, the modes in the spectral region of band III and IV are slightly shifted $\left(1237 \mathrm{~cm}^{-1}\right.$ and $1012 / 1003 \mathrm{~cm}^{-1}$ for $\mathrm{Au}_{2}\left(\mathrm{C}_{2} \mathrm{H}_{4}\right)^{+}$compared to $1260 \mathrm{~cm}^{-1}$ and $998 / 992 \mathrm{~cm}^{-1}$ for
$\left.\mathrm{Au}_{2}\left(\mathrm{C}_{2} \mathrm{H}_{4}\right)_{2}{ }^{+}\right)$which prevents the cancelation of the signals and results in the detection of bands III and IV in the IRMPD spectrum of $\mathrm{Au}_{2}\left(\mathrm{C}_{2} \mathrm{H}_{4}\right)^{+}$.

Finally, it can be concluded that up to two ethylene molecules bind exclusively to $\mathrm{Au}_{2}{ }^{+}$in a $\square$-bonded configuration. Although the coexistence of the di- $\square$-bonded isomer iso 2,1-b for $\mathrm{Au}_{2}\left(\mathrm{C}_{2} \mathrm{H}_{4}\right)^{+}$cannot be completely excluded based on the IR-MPD spectrum, the results for $\mathrm{Au}_{2}\left(\mathrm{C}_{2} \mathrm{H}_{4}\right)_{2}{ }^{+}$render the existence of such an isomer rather unlikely.

\section{2 $\mathrm{Au}_{2}{ }^{+}$Mediated $\mathrm{C}-\mathrm{C}$ and $\mathrm{C}-\mathrm{H}$ Bond Activation of $\mathrm{C}_{2} \mathrm{H}_{4}$}

For the potential catalytic oxidation of ethylene to either acetaldehyde or epoxide the activation of the ethylene molecule represents an important first step. In order to gain insight into such a bond activation mechanism upon adsorption on the gold cluster, the electronic structure of $\mathrm{Au}_{2}\left(\mathrm{C}_{2} \mathrm{H}_{4}\right)^{+}$was theoretically investigated. Figure 2 displays the electronic density of states (DOS) for an isolated $\mathrm{Au}_{2}{ }^{+}$ cluster (right), a free $\mathrm{C}_{2} \mathrm{H}_{4}$ molecule (left), and the corresponding $\square$-bonded $\mathrm{Au}_{2}\left(\mathrm{C}_{2} \mathrm{H}_{4}\right)^{+}$complex (that represents the minimum energy structure as shown in Section 3.1). The DOS is shown separately for spin up (majority spin) and down (minority spin) electrons. Also shown are all the occupied and the lowest energy unoccupied Kohn-Sham (KS) orbitals of $\mathrm{C}_{2} \mathrm{H}_{4}$ as well as selected $\mathrm{KS}$ orbitals for $\mathrm{Au}_{2}{ }^{+}$ and $\mathrm{Au}_{2}\left(\mathrm{C}_{2} \mathrm{H}_{4}\right)^{+}$.

The $5 \mathrm{~d}^{10} 6 \mathrm{~s}^{1}$ valence electron configuration of the gold atom leads to a doublet state of $\mathrm{Au}_{2}{ }^{+}$with a singly occupied orbital of mostly s-like character lying close to the Fermi energy $\square_{\mathrm{F}}$. Thus, both the highest occupied molecular orbital (HOMO) and the lowest unoccupied molecular orbital (LUMO) of $\mathrm{Au}_{2}^{+}$have s-like character, whereas all energetically lower-lying orbitals have mainly d-like character.

The DOS and selected KS orbitals shown in the middle of Figure 2 illustrate the modification of the electronic structure of $\mathrm{C}_{2} \mathrm{H}_{4}$ and $\mathrm{Au}_{2}{ }^{+}$upon formation of $\mathrm{Au}_{2}\left(\mathrm{C}_{2} \mathrm{H}_{4}\right)^{+}$. The gray filled peaks of the $\mathrm{Au}_{2}\left(\mathrm{C}_{2} \mathrm{H}_{4}\right)^{+}$DOS correspond to the states of the entire cluster complex, whereas the green areas correspond to the states localized on the $\mathrm{C}_{2} \mathrm{H}_{4}$ molecule.

The two main factors that guide the analysis of the binding of the ethylene molecule to the gold cluster cation, are the symmetry of the interacting orbitals of the two partners, and their relative energies, with bond formation requiring proper orbital symmetries and energetic proximity of the two participating orbitals. The three orbitals below -15 $\mathrm{eV}$ as well as the orbital at about $-12.5 \mathrm{eV}$ closely resemble the $\mathrm{C}-\mathrm{H}$ bond forming orbitals $\left(\square^{\square}\left(\mathrm{CH}_{2}\right), \quad \square^{\square}\left(\mathrm{CH}_{2}\right)\right.$, $\square^{\square}\left(\mathrm{CH}_{2}\right)$, and $\left.\square^{\square}\left(\mathrm{CH}_{2}\right)\right)$ of the free ethylene molecule. In marked contrast, the $\mathrm{C}=\mathrm{C}$ double bond forming orbitals $\square(\mathrm{CC})$ and 


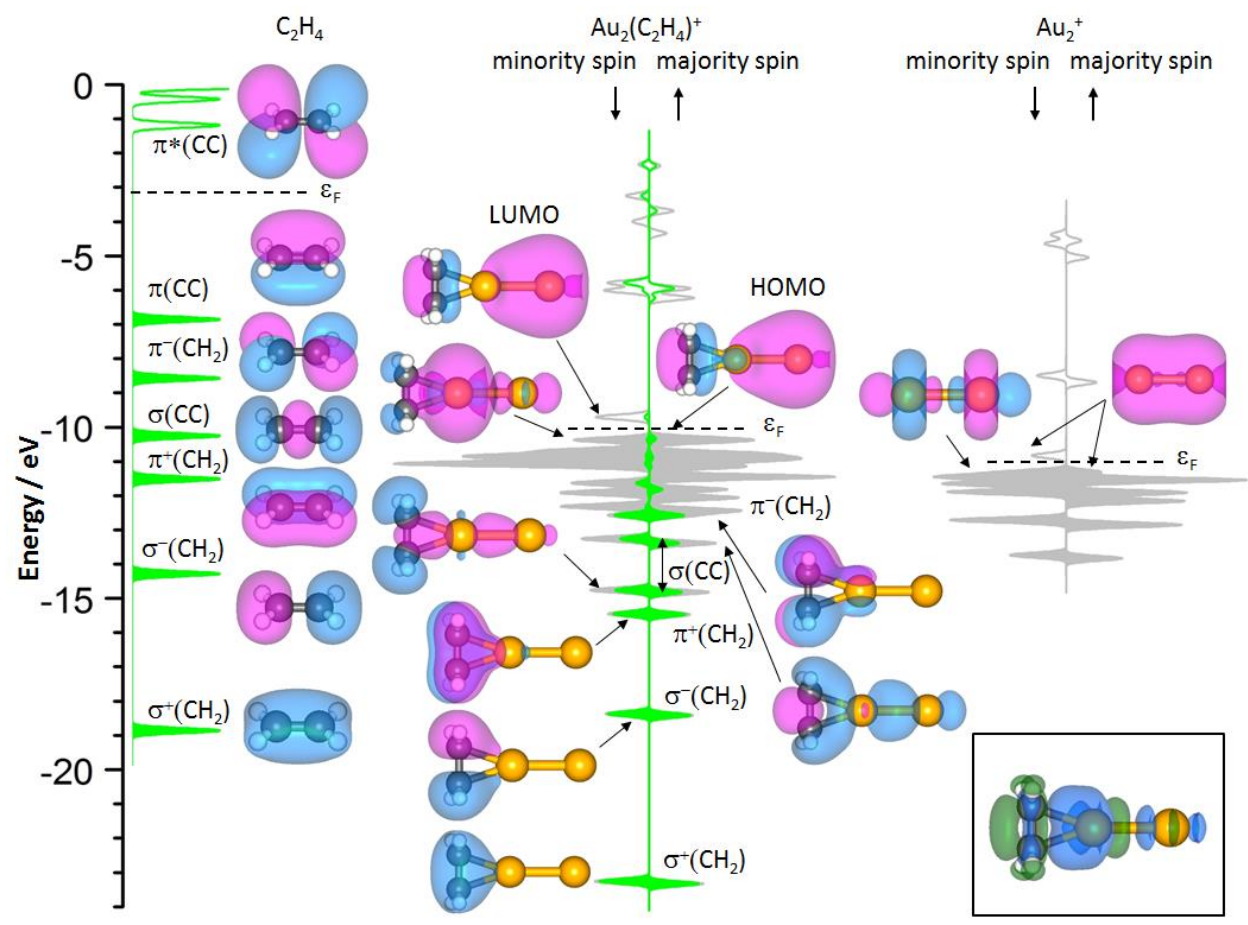

Figure 2: Electronic structure, represented by the density of states (DOS) and isosurfaces (encompassing $90 \%$ of the electron density) of selected KS orbitals (with positive and negative values depicted in blue and pink, respectively) for free $\mathrm{C}_{2} \mathrm{H}_{4}\left(\mathrm{left}\right.$ ), the free $\mathrm{Au}_{2}{ }^{+}$cluster (right) and the $\square$-bonded $\mathrm{Au}_{2}\left(\mathrm{C}_{2} \mathrm{H}_{4}\right)^{+}$complex (middle). The DOS is shown separately for spin up and down electrons. For occupied states (energy below the Fermi level $\varepsilon_{F}$, horizonal dashed line) the area under the DOS curve is filled. The gray DOS curves for $\mathrm{Au}_{2}\left(\mathrm{C}_{2} \mathrm{H}_{4}\right)^{+}$ correspond to the total charge of the full complex, and the green curves to charge localized on the $\mathrm{C}_{2} \mathrm{H}_{4}$ molecule. The inset shows the charge density difference isosurfaces (encompassing $90 \%$ of the charge) for $\mathrm{Au}_{2}\left(\mathrm{C}_{2} \mathrm{H}_{4}\right)^{+}$; blue regions correspond to excess electronic charge, and green ones correspond to charge deficiency.

$\square(\mathrm{CC})$ of free ethylene molecule appear to mix with the $\mathrm{Au}_{2}{ }^{+}$ orbitals. This mixing leads to a considerable shift of the Fermi energy of ethylene to lower energies.

Most importantly for the interaction of $\mathrm{C}_{2} \mathrm{H}_{4}$ with $\mathrm{Au}_{2}{ }^{+}$ are, however, the states close to the Fermi level. The HOMO of the complex $\mathrm{Au}_{2}\left(\mathrm{C}_{2} \mathrm{H}_{4}\right)^{+}$is formed by interaction of the occupied ethylene $\square$ (CC) orbital with the (s-like) HOMO of $\mathrm{Au}_{2}{ }^{+}$while the LUMO of $\mathrm{Au}_{2}\left(\mathrm{C}_{2} \mathrm{H}_{4}\right)^{+}$is formed by interaction of the occupied ethylene $\square$ (CC) orbital with the (s-like) LUMO of $\mathrm{Au}_{2}{ }^{+}$. This shift of part of the ethylene $\square$ (CC) orbital above $\square_{\text {F }}$ results in a partial de-population of the bonding $\square(\mathrm{CC})$ orbital and a weakening of the ethylene $\mathrm{C}=\mathrm{C}$ bond. At the same time, the DOS spectrum does not indicate any contribution of the unoccupied ethylene antibonding $\square \square$ (CC) orbital to the binding of the molecule to the gold cluster. Consequently, we conclude that the interaction of $\mathrm{Au}_{2}{ }^{+}$with $\mathrm{C}_{2} \mathrm{H}_{4}$ is chiefly governed by electron charge donation from $\mathrm{C}_{2} \mathrm{H}_{4}$ to gold while a gold-to- $\mathrm{C}_{2} \mathrm{H}_{4}$ back-donation is not observed. This charge donation leads to an elongation of the $\mathrm{C}-\mathrm{C}$ bond to $1.403 \AA$ compared to 1.333 $\AA$ for the free $\mathrm{C}_{2} \mathrm{H}_{4}$ molecule (1.339 $\AA$ experimental [13]) .

This net charge transfer can also be seen in the charge density difference plot shown in the inset of Figure 2. The blue and green areas corresponding to excess electron charge and charge deficiency, respectively, clearly depict electron transfer from the occupied ethylene $\square$ (CC) orbital to the gold dimer. The net charge transfer is determined from the calculated charge difference resulting from the interaction of $\mathrm{Au}_{2}{ }^{+}$and $\mathrm{C}_{2} \mathrm{H}_{4}$ (cf. Section 2.2) and is estimated to amount to $0.18 \mathrm{e}$.

The DOS spectrum shows the interaction of the ethylene $\mathrm{C}=\mathrm{C}$ bond forming orbitals, $\square(\mathrm{CC})$ and $\square(\mathrm{CC})$, with $\mathrm{Au}_{2}{ }^{+}$ while the $\mathrm{C}-\mathrm{H}$ bond forming orbitals, $\square^{\square}\left(\mathrm{CH}_{2}\right), \square^{\square}\left(\mathrm{CH}_{2}\right)$, $\square^{\square}\left(\mathrm{CH}_{2}\right)$, and $\square^{\square}\left(\mathrm{CH}_{2}\right)$, hardly mix with the gold orbitals. This leads to an activation of the $\mathrm{C}=\mathrm{C}$ double bond while the $\mathrm{C}-\mathrm{H}$ bond is not activated (compare $d(\mathrm{C}-\mathrm{H})=1.094 \AA$ in $\mathrm{Au}_{2}\left(\mathrm{C}_{2} \mathrm{H}_{4}\right)^{+}$to $d(\mathrm{C}-\mathrm{H})=1.092 \AA$ in free $\left.\mathrm{C}_{2} \mathrm{H}_{4}\right)$.

Recently, we have demonstrated in a combined IR-MPD spectroscopic and theoretical investigation that the $\mathrm{C}-\mathrm{H}$ bond of one methane molecule $\mathrm{CH}_{4}$ can get activated upon adsorption on small cationic gold clusters [58]. It has been shown that the barrier for dissociation of the strong $\mathrm{C}-\mathrm{H}$ bond can be reduced from about $4.5 \mathrm{eV}$ for free $\mathrm{CH}_{4}$ to 1.36 


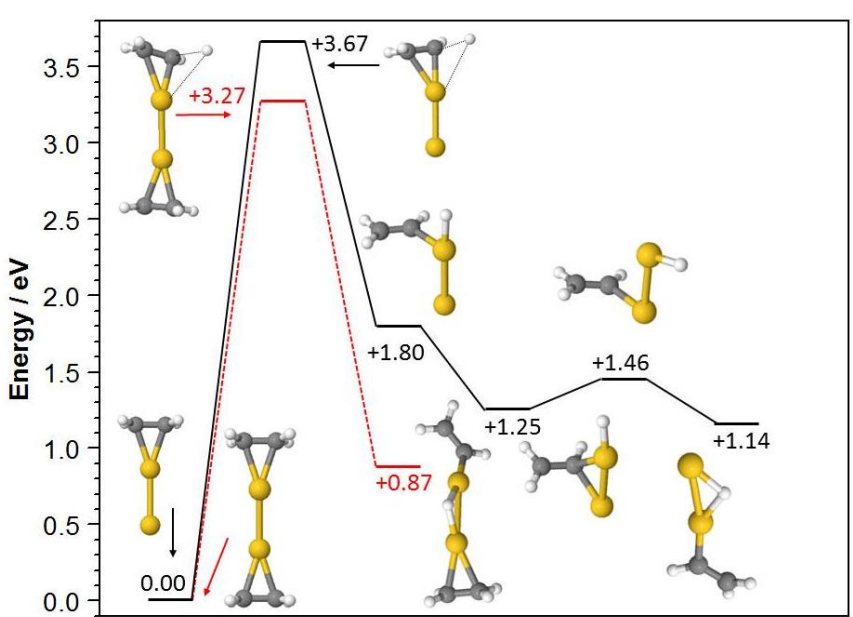

Figure 3: Calculated energy profile for the dissociation of one $\mathrm{C}-\mathrm{H}$ bond of $\mathrm{C}_{2} \mathrm{H}_{4}$ upon adsorption of one (black curve) and two (red curve) $\mathrm{C}_{2} \mathrm{H}_{4}$ molecules on $\mathrm{Au}_{2}{ }^{+}$. The black and red numbers denote the relative energies of the transition states and local minima in $\mathrm{eV}$ with respect to that of the minimum energy complexes $\mathrm{Au}_{2}\left(\mathrm{C}_{2} \mathrm{H}_{4}\right)^{+}$and $\mathrm{Au}_{2}\left(\mathrm{C}_{2} \mathrm{H}_{4}\right)_{2}{ }^{+}$, respectively. Structural models: Au yellow, $\mathrm{C}$ gray, $\mathrm{H}$ white.

$\mathrm{eV}$ upon adsorption of $\mathrm{Au}_{3}{ }^{+}$, followed by the formation of a hydrido methyl complex. This barrier is found here to be even smaller $(0.63 \mathrm{eV})$ for $\mathrm{CH}_{4}$ adsorbed on $\mathrm{Au}_{2}{ }^{+}$, with the resulting hydrido methyl complex found to be only $0.05 \mathrm{eV}$ less favourable than the simple adsorption complex. A similar $\mathrm{C}-\mathrm{H}$ bond dissociation mechanism has also been theoretically investigated for $\mathrm{C}_{2} \mathrm{H}_{4}$ and is shown in Figure 3. The limited mixing between $\mathrm{CH}_{2}$ binding orbitals and $\mathrm{Au}_{2}{ }^{+}$ leads to a very high activation barrier of $3.67 \mathrm{eV}$ (compare to the C-H bond strength of $4.85 \mathrm{eV}$ [13] of free $\mathrm{C}_{2} \mathrm{H}_{4}$ ) for C-H bond dissociation. For the resulting hydrido vinyl complex three different stable isomeric structures have been identified which are $1.80 \mathrm{eV}, 1.25 \mathrm{eV}$, and $1.14 \mathrm{eV}$ higher in energy than the simple $\square$-bonded adsorption complex. Thus, the high activation energy for $\mathrm{C}-\mathrm{H}$ bond dissociation makes the formation of hydrido vinyl isomers highly unlikely which is further supported by the experimental IR-MPD spectra. Figure 2 shows the calculated vibrational spectrum of the energetically most favourable hydrido vinyl complex (iso 2,1-c) which strongly disagrees with the experimental IRMPD spectrum. The experimental spectrum does not show any indication for the coexistence of other theoretically found hydrido vinyl structures in the cluster beam either (cf. Figure S1).

Figure 3 also shows that coadsorption of a second ethylene molecule (red curve) brings about a slight reduction of the barrier for $\mathrm{C}-\mathrm{H}$ bond dissociation to $3.27 \mathrm{eV}$. In this case only one stable isomeric structure for the hydrido vinyl complex was found, which is $0.87 \mathrm{eV}$ less stable than the $\square$ bonded adsorption complex. The formation of other isomeric structures as in the case of $\mathrm{Au}_{2}\left(\mathrm{C}_{2} \mathrm{H}_{4}\right)^{+}$appears to be impossible due to the blockage of the second $\mathrm{Au}$ atom by the second $\mathrm{C}_{2} \mathrm{H}_{4}$ molecule. Despite the slight reduction of the energy barrier, the formation of the hydrido vinyl complex is

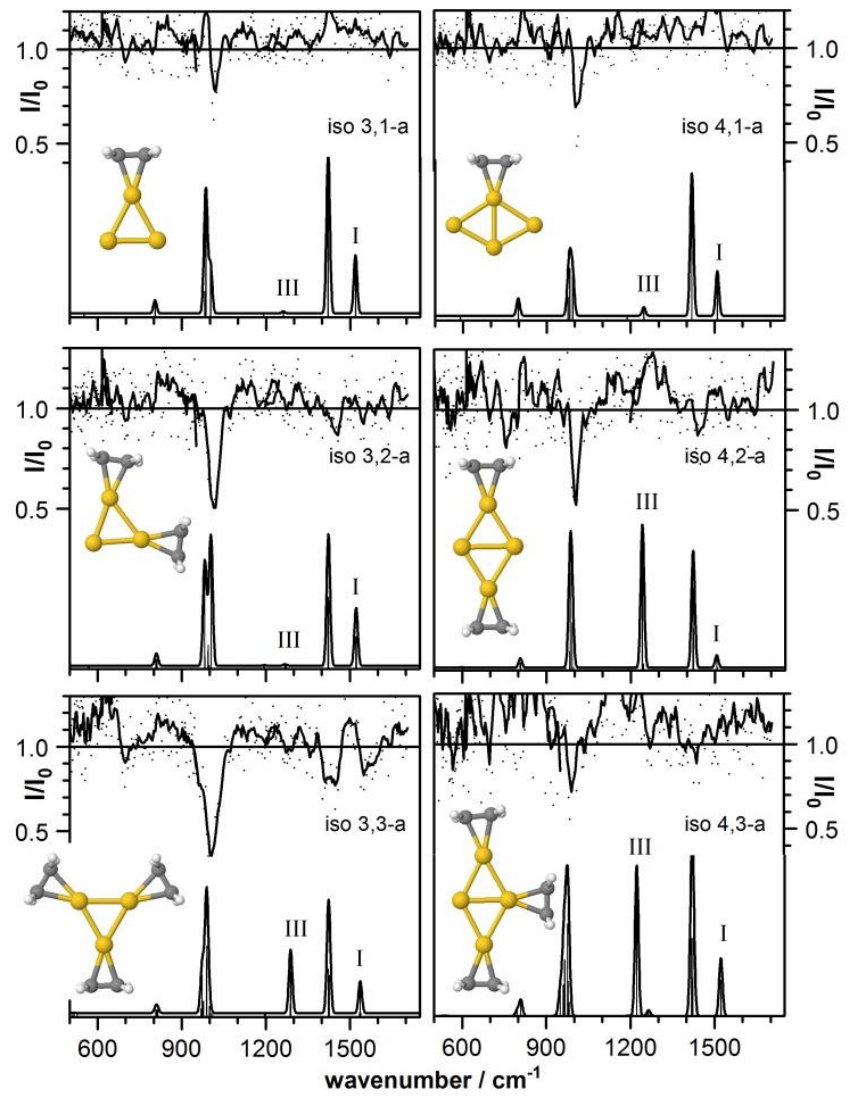

Figure 4: IR-MPD spectra of (left column) $\mathrm{Au}_{3}\left(\mathrm{C}_{2} \mathrm{H}_{4}\right)_{\mathrm{y}}{ }^{+}(\mathrm{y}=1-3)$ and (right column $) \mathrm{Au}_{4}\left(\mathrm{C}_{2} \mathrm{H}_{4}\right)_{\mathrm{y}}{ }^{+}(\mathrm{y}=1-4)$ as well as calculated vibrational spectra of the lowest energy isomers. Structural models: Au yellow, $\mathrm{C}$ gray, $\mathrm{H}$ white.

highly unlikely, in agreement with the IR-MPD spectrum of $\mathrm{Au}_{2}\left(\mathrm{C}_{2} \mathrm{H}_{4}\right)_{2}{ }^{+}$showing no similarity to the calculated vibrational spectrum of such a hydrido vinyl complex (cf. Figure S1, iso 2,2-e).

This obvious difference in the $\mathrm{C}-\mathrm{H}$ bond activation of $\mathrm{CH}_{4}$ and $\mathrm{C}_{2} \mathrm{H}_{4}$ is caused by the considerable different binding of these two molecules to the gold clusters. As discussed above, ethylene binds via mixing of the $\mathrm{C}=\mathrm{C}$ bond forming orbitals $\square(\mathrm{CC})$ and $\square(\mathrm{CC})$ with the gold orbitals, while $\mathrm{CH}_{4}$ binds via mixing of $\mathrm{C}-\mathrm{H}$ bond forming orbitals with the gold orbitals $[58,59]$. This leads to an activation of the $\mathrm{C}=\mathrm{C}$ double bond of ethylene (with the $\mathrm{C}-\mathrm{H}$ bond remaining rather unaffected) in contrast to an activation of the $\mathrm{C}-\mathrm{H}$ bond in methane.

\subsection{IR-MPD Spectra of $A u_{3}\left(C_{2} H_{4}\right)_{y}{ }^{+}$and $\mathrm{Au}_{4}\left(\mathrm{C}_{2} \mathrm{H}_{4}\right)_{y}{ }^{+}$ Complexes}

To gain insight into a possible cluster size dependent goldethylene interaction we have also investigated the complexes $\mathrm{Au}_{3}\left(\mathrm{C}_{2} \mathrm{H}_{4}\right)_{\mathrm{y}}{ }^{+}(\mathrm{y}=1-3)$ and $\mathrm{Au}_{4}\left(\mathrm{C}_{2} \mathrm{H}_{4}\right)_{\mathrm{y}}{ }^{+}(\mathrm{y}=1-3)$. Figure 4 shows the IR-MPD spectra together with the theoretically obtained vibrational spectra of the minimum energy structures. For all studied complexes, the $\square$-bonded 
configuration is energetically more favorable than the di- $\square$ bonded configuration which is in agreement with previous
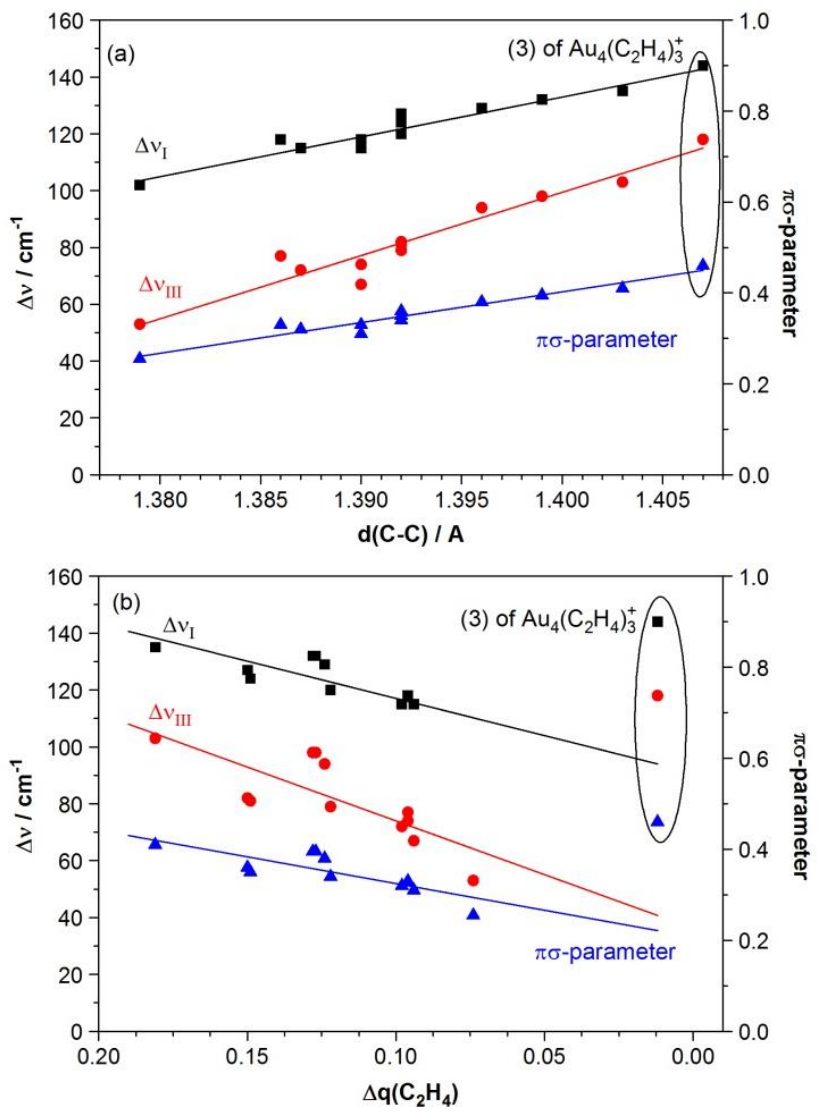

Figure 5: Calculated shift of the $\mathrm{C}_{2} \mathrm{H}_{4}$ vibrations labeled I ( $\square \square$ I, black squares) and III ( $\square \square$ III, red circles) in Figures 1 and 4 compared to the frequencies of free $\mathrm{C}_{2} \mathrm{H}_{4}$ as well as the corresponding $\square \square$-parameter (blue triangles) as a function of (a) the C-C bond length $d(\mathrm{C}-\mathrm{C})$ and (b) the estimated net electron transfer from $\mathrm{C}_{2} \mathrm{H}_{4}$ to the cluster upon adsorption. The lines are drawn to guide the eye.

studies [31, 36]. For $\mathrm{Au}_{3}\left(\mathrm{C}_{2} \mathrm{H}_{4}\right)^{+}$the di- $\square$-bonded isomer is $1.04 \mathrm{eV}$ higher in energy than the $\square$-bonded isomer, whereas for $\mathrm{Au}_{3}\left(\mathrm{C}_{2} \mathrm{H}_{4}\right)_{2}{ }^{+}$and $\mathrm{Au}_{3}\left(\mathrm{C}_{2} \mathrm{H}_{4}\right)_{3}{ }^{+}$all structures with one or more di- $\square$-bonded $\mathrm{C}_{2} \mathrm{H}_{4}$ molecules have not been found to be minima on the potential energy surface. The energetic difference is strongly reduced for $\mathrm{Au}_{4}\left(\mathrm{C}_{2} \mathrm{H}_{4}\right)^{+}$, where the di$\square$-bonded isomer is only $0.31 \mathrm{eV}$ higher in energy than the $\square$-bonded one. $\mathrm{Au}_{4}\left(\mathrm{C}_{2} \mathrm{H}_{4}\right)_{2}{ }^{+}$and $\mathrm{Au}_{4}\left(\mathrm{C}_{2} \mathrm{H}_{4}\right)_{3}{ }^{+}$isomers containing one di- $\square$-bonded $\mathrm{C}_{2} \mathrm{H}_{4}$ molecule are $0.42 \mathrm{eV}$ and $0.37 \mathrm{eV}$ higher in energy than the isomers containing only $\square \square$-bonded $\mathrm{C}_{2} \mathrm{H}_{4}$ (cf. Figure S2). The considerably greater thermodynamic instability of the $\mathrm{Au}_{3}\left(\mathrm{C}_{2} \mathrm{H}_{4}\right)^{+}$di- $\square$ bonded isomer $(1.04 \mathrm{eV})$ compared to $\mathrm{Au}_{2}\left(\mathrm{C}_{2} \mathrm{H}_{4}\right)^{+}(0.36 \mathrm{eV})$ and $\mathrm{Au}_{4}\left(\mathrm{C}_{2} \mathrm{H}_{4}\right)^{+}(0.31 \mathrm{eV})$ is in agreement with a previous study and has been explained by the closed-shell electronic structure of $\mathrm{Au}_{3}{ }^{+}$(forming a fully occupied superatom $1 \mathrm{~S}$ orbital from the two occupied $6 \mathrm{~s}^{1}$ electrons in the tri-atomic gold cation) which makes charge back-donation from the cluster to $\mathrm{C}_{2} \mathrm{H}_{4}$ unfavorable, a process which is crucial for sigma-bond formation [31].
All IR-MPD spectra of Figure 4 show a strong band around $1000 \mathrm{~cm}^{-1}$, similar to the frequency of the dominant bands in the $\mathrm{Au}_{2}\left(\mathrm{C}_{2} \mathrm{H}_{4}\right)_{\mathrm{y}}{ }^{+}$spectra. Consistent with these results, this band can again be explained by the $\mathrm{CH}_{2}$ wagging modes of the $\mathrm{Au}_{\mathrm{x}}\left(\mathrm{C}_{2} \mathrm{H}_{4}\right)_{\mathrm{y}}{ }^{+}$minimum energy structures. The IR-MPD spectrum of $\mathrm{Au}_{3}\left(\mathrm{C}_{2} \mathrm{H}_{4}\right)_{2}{ }^{+}$exhibits an additional signal at $1452 \mathrm{~cm}^{-1}$ which can be described by the $\mathrm{CH}_{2}$ scissor mode of the minimum energy structure. The spectrum of $\mathrm{Au}_{3}\left(\mathrm{C}_{2} \mathrm{H}_{4}\right)_{3}{ }^{+}$exhibits two more signals at $1570 \mathrm{~cm}^{-1}$ and $1435 \mathrm{~cm}^{-1}$ which are in agreement with one of the theoretically obtained mixed $\mathrm{C}-\mathrm{C}$ stretch $/ \mathrm{CH}_{2}$ scissor motions of $\mathrm{C}_{2} \mathrm{H}_{4}$ and the $\mathrm{CH}_{2}$ scissor modes of the minimum energy isomer. Similarly, $\mathrm{Au}_{4}\left(\mathrm{C}_{2} \mathrm{H}_{4}\right)_{2}{ }^{+}$shows two more weak bands at $1445 \mathrm{~cm}^{-1}$ and $766 \mathrm{~cm}^{-1}$ which can be described by the $\mathrm{CH}_{2}$ scissor mode and the $\mathrm{CH}_{2}$ rock mode of the minimum energy structure. All remaining theoretically predicted modes are not observed in the experimental spectra, which is most likely caused by overlapping fragmentation channels.

Nevertheless, based on these spectra, any substantial population of a di- $\square$-bonded isomer can be excluded for all investigated $\mathrm{Au}_{\mathrm{x}}\left(\mathrm{C}_{2} \mathrm{H}_{4}\right)_{\mathrm{y}}{ }^{+}$(cf. Figures $\mathrm{S} 3$ and $\mathrm{S} 4$ ).

\subsection{Interplay of Charge Donation/Back-Donation}

As shown above, the adsorption of ethylene on $\mathrm{Au}_{2}{ }^{+}$leads to a charge donation from the occupied ethylene $\square$ (CC) orbital to an unoccupied $\mathrm{Au}_{2}{ }^{+}$orbital which results in an elongation of the $\mathrm{C}=\mathrm{C}$ bond from $1.333 \AA$ to $1.403 \AA$. Such a bond elongation should be directly reflected in the $\mathrm{C}=\mathrm{C}$ bond stretch frequencies. As discussed above this stretch mode is coupled to a $\mathrm{CH}_{2}$ scissor mode leading to two mixed vibrational modes labeled as I and III in Figures 1 and 4.

Figure 5a displays the shift of these modes as a function of the calculated $\mathrm{C}-\mathrm{C}$ bond distance for all investigated goldethylene complexes. The frequency shifts $\square \square$ I and $\square \square_{\text {III }}$ are calculated as the difference between the theoretically obtained frequencies for the individual $\mathrm{C}_{2} \mathrm{H}_{4}$ molecules in the adsorption complexes $\mathrm{Au}_{\mathrm{x}}\left(\mathrm{C}_{2} \mathrm{H}_{4}\right)_{\mathrm{y}}{ }^{+}$and the value of the free $\mathrm{C}_{2} \mathrm{H}_{4}$ molecule. Indeed, Figure 5a shows a linear correlation between $\square \square$ I and $\square \square$ III and the C-C bond distance.

Furthermore, we determine the $\square \square$-parameter in the form as introduced by Stuve and Madix [60]. This parameter is calculated as the sum of the relative frequency reductions of $\square_{\text {I }}$ and $\square$ III upon adsorption of $\mathrm{C}_{2} \mathrm{H}_{4}$ on the cluster. The $\square \square$ parameter is constructed such that it is zero for $\mathrm{sp}^{2}$ hybridized free $\mathrm{C}_{2} \mathrm{H}_{4}$ and unity for $\mathrm{C}_{2} \mathrm{H}_{4} \mathrm{Br}_{2}$ as representative for di- $\square$-bonding. Thus, the $\square \square$-parameter is a measure of the extent of $\mathrm{C}_{2} \mathrm{H}_{4}$ re-hybridization upon adsorption. The blue curve in Figure 5a shows that the theoretically obtained $\square \square$-parameters for all $\mathrm{C}_{2} \mathrm{H}_{4}$ molecules in the investigated $\mathrm{Au}_{\mathrm{x}}\left(\mathrm{C}_{2} \mathrm{H}_{4}\right)_{\mathrm{y}}{ }^{+}$complexes range between 0.26 and 0.46 . These values are typical for $\square$-bonded systems [60] and indicate 
only little re-hybridization. We also note that the $\square \square \square$ parameter correlates linearly with the $\mathrm{C}-\mathrm{C}$ distance.
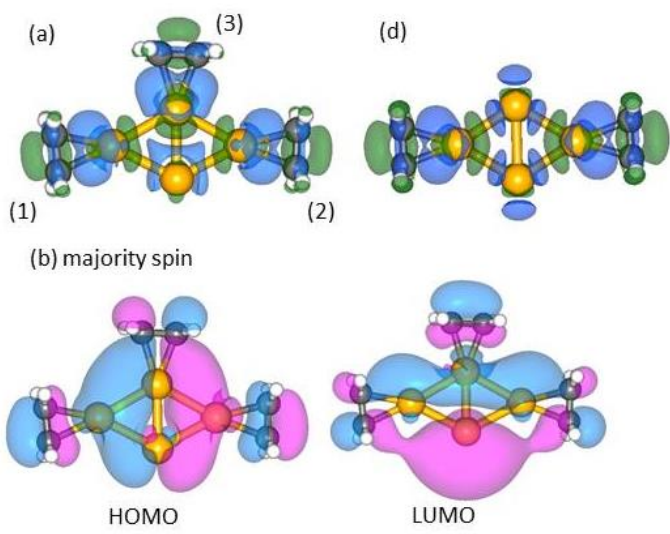

(2)
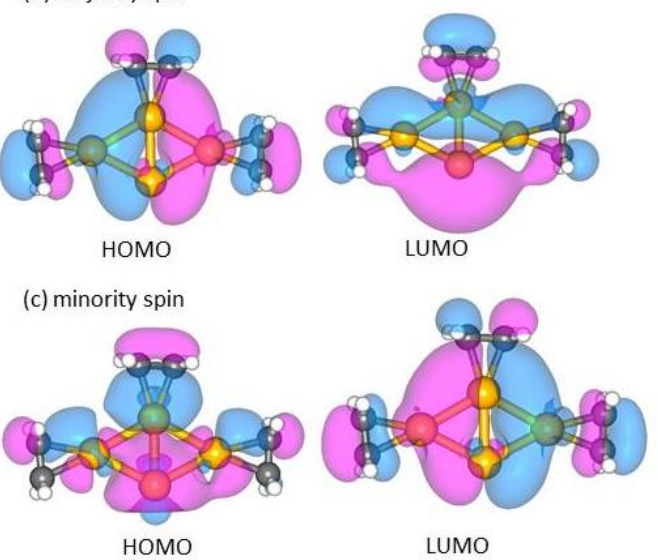

Figure 6: (a) and (d): Charge density difference isosurfaces (encompassing $90 \%$ of the charge) for $\mathrm{Au}_{4}\left(\mathrm{C}_{2} \mathrm{H}_{4}\right)_{3}{ }^{+}$and $\mathrm{Au}_{4}\left(\mathrm{C}_{2} \mathrm{H}_{4}\right)_{2}{ }^{+}$, indicating electronic charge excess (blue regions) or deficiency (green) (b) and (c): Calculated isosurfaces (containing $90 \%$ of the wave function) of some $\mathrm{KS}$ orbitals of $\mathrm{Au}_{4}\left(\mathrm{C}_{2} \mathrm{H}_{4}\right)_{3}{ }^{+}$, indicating positive (blue) and negative (pink) values of the wave function.

Since the elongation of the $\mathrm{C}-\mathrm{C}$ bond distance is caused by $\mathrm{C}_{2} \mathrm{H}_{4}$ charge donation we also investigated the relation between the net electron transfer from $\mathrm{C}_{2} \mathrm{H}_{4}$ to the gold clusters (cf. Section 2.2) and the frequency shifts $\square \square_{\mathrm{I}}$ and $\square \square$ III as well as the $\square \square$-parameter. Figure 5b shows that all three parameters also correlate linearly with the estimated net electron transfer except for one $\mathrm{C}_{2} \mathrm{H}_{4}$ molecule (marked by a black circle). This ethylene molecule corresponds to the third $\mathrm{C}_{2} \mathrm{H}_{4}$ molecule adsorbed on a threefold coordinated $\mathrm{Au}$ atom of $\mathrm{Au}_{4}{ }^{+}$(labeled (3) in Figure 6a).

The charge density difference isosurfaces of $\mathrm{Au}_{4}\left(\mathrm{C}_{2} \mathrm{H}_{4}\right)_{3}{ }^{+}$ displayed in Figure 6a show that all three $\mathrm{C}_{2} \mathrm{H}_{4}$ molecules bind via a net electron transfer from $\mathrm{C}_{2} \mathrm{H}_{4}$ (green areas indicate electron deficiency) to the gold cluster (blue areas correspond to electron excess). However, the net charge transfer of the $\mathrm{C}_{2} \mathrm{H}_{4}$ molecules labeled (1) and (2) is estimated to amount to 0.10 e each while it is reduced to approximately $0.01 \mathrm{e}$ for the molecule labeled (3). To understand the rather strong $\mathrm{C}=\mathrm{C}$ bond activation (large $\square \square_{\mathrm{I}}$ and $\square \square$ III as well as a $\square \square \square$ parameter of 0.46) despite such a small net electron transfer, the KS orbitals near the Fermi energy must be considered.

Figure $6 \mathrm{~b}$ (where we plot the isosurfaces of the HOMO KS wavefunctions) shows that the HOMO of the majority spin is formed by mixing $\mathrm{Au}_{4}{ }^{+}$orbitals with the occupied $\square(\mathrm{CC})$ orbitals for molecules (1) and (2), whereas they are mixed with the unoccupied $\square \square$ (CC) of molecule (3); for the identity and labels of the free $\mathrm{C}_{2} \mathrm{H}_{4}$ molecule KS orbitals, see the right panel of Figure 2. The majority spin LUMO is formed by mixing $\mathrm{Au}_{4}^{+}$orbitals with the unoccupied $\square \square$ (CC) orbitals of molecules (1) and (2) but with the occupied $\square$ (CC) orbital of molecule (3). In marked contrast, the minority spin HOMO (cf. Figure 6c) is mainly formed by mixing gold orbitals with the occupied $\square$ (CC) orbital of molecule (3) with rather small contributions of the $\square \square$ (CC) orbitals of molecules (1) and (2). Finally, the minority spin LUMO is formed by mixing gold orbitals with the occupied $\square$ (CC) orbital of molecule (1) and (2) as well as with the $\square \square$ (CC) orbital of molecule (3).

The contributions of the occupied $\square$ (CC) orbitals of molecules (1) and (2) to the majority spin HOMO and minority spin LUMO show that the binding of these two molecules is dominated by $\mathrm{C}_{2} \mathrm{H}_{4}$-to-gold charge donation which leads to a partial de-population of the $\square$ (CC) orbitals. The contributions of the unoccupied $\square \square(\mathrm{CC})$ orbitals of molecules (1) and (2) to the minority spin HOMO also indicate some gold-to- $\mathrm{C}_{2} \mathrm{H}_{4}$ back-donation. This additional back-donation is, however, small and the binding is clearly dominated by $\mathrm{C}_{2} \mathrm{H}_{4}$-to-gold charge donation. We note here, that no charge back-donation has been observed by us for the $\mathrm{Au}_{2}\left(\mathrm{C}_{2} \mathrm{H}_{4}\right)^{+}$complex that we discussed above.

In marked contrast, gold-to- $\mathrm{C}_{2} \mathrm{H}_{4}$ charge back-donation appears to play a much more important role for molecule (3). The contribution of the occupied $\square$ (CC) orbital to the minority spin HOMO and the majority spin LUMO indicates $\mathrm{C}_{2} \mathrm{H}_{4}$ (3)-to-gold charge donation. In addition, the majority spin HOMO and minority spin LUMO contain contributions from the unoccupied $\square \square$ (CC) orbital of $\mathrm{C}_{2} \mathrm{H}_{4}$ (3) indicating gold-to- $\mathrm{C}_{2} \mathrm{H}_{4}$ (3) charge back-donation. This concurrent charge donation/back-donation results in a rather small net electron transfer of around 0.01e. Since, however, both charge donation and back-donation lead to an activation of the $\mathrm{C}=\mathrm{C}$ bond, this results in the largest observed $\mathrm{C}=\mathrm{C}$ bond distance of $1.407 \AA$ and thus in rather large values of $\square \square_{\mathrm{I}}$ and $\square \square$ III and the $\square \square$-parameter.

This rather strong activation of the $\mathrm{C}=\mathrm{C}$ bond of molecule (3) in $\mathrm{Au}_{4}\left(\mathrm{C}_{2} \mathrm{H}_{4}\right)_{3}{ }^{+}$is caused by a cooperative effect of the three coadsorbed ethylene molecules. Adsorption of one $\mathrm{C}_{2} \mathrm{H}_{4}$ molecule on the threefold coordinated $\mathrm{Au}$ atom of the bare $\mathrm{Au}_{4}{ }^{+}$cluster (which represents the minimum energy structure, cf. Figure S2) leads to an estimated net charge transfer of 0.12 e from ethylene to gold which is distributed over the three empty gold atoms (estimated to be about 0.05 e on each Au atom). Charge back-donation is found to occur but only plays a minor role. Adsorption of two $\mathrm{C}_{2} \mathrm{H}_{4}$ molecules results in the structure displayed in Figure $6 \mathrm{~d}$ with both ethylene molecules bound to the twofold coordinated $\mathrm{Au}$ atoms. The estimated net charge transfer from each $\mathrm{C}_{2} \mathrm{H}_{4}$ molecule to the clusters is $0.13 \mathrm{e}$. The charge density 
isosurfaces (see Figure 6d) show that this leads to charge depletion on the binding twofold coordinated $\mathrm{Au}$ atoms (estimated to be about 0.09 e) and an estimated excess charge of $0.21 \mathrm{e}$ on each of the empty threefold coordinated $\mathrm{Au}$ atoms. This accumulation of excess charge on the threefold coordinated gold atoms enables the charge back-donation upon coadsorption of the third $\mathrm{C}_{2} \mathrm{H}_{4}$ molecule and the resulting increased $\mathrm{C}=\mathrm{C}$ bond activation. This finding is in agreement with a previous study of anionic gold-ethylene complexes which showed a slightly higher $\mathrm{C}=\mathrm{C}$ bond activation than the corresponding cationic species [31].

Inspection of the DOS as well as the KS orbitals of all investigated $\mathrm{Au}_{\mathrm{x}}\left(\mathrm{C}_{2} \mathrm{H}_{4}\right)_{\mathrm{y}}{ }^{+}$complexes show that the interaction of the gold cations with all $\mathrm{C}_{2} \mathrm{H}_{4}$ is dominated by electron donation. While for $\mathrm{Au}_{2}\left(\mathrm{C}_{2} \mathrm{H}_{4}\right)_{\mathrm{y}}{ }^{+}(\mathrm{y}=1,2)$ and $\mathrm{Au}_{3}\left(\mathrm{C}_{2} \mathrm{H}_{4}\right)_{\mathrm{y}}{ }^{+}(\mathrm{y}=2,3)$ no charge back-donation is observed, small back-donation is found for $\mathrm{Au}_{3}\left(\mathrm{C}_{2} \mathrm{H}_{4}\right)^{+}, \mathrm{Au}_{4}\left(\mathrm{C}_{2} \mathrm{H}_{4}\right)^{+}$, $\mathrm{Au}_{4}\left(\mathrm{C}_{2} \mathrm{H}_{4}\right)_{2}{ }^{+}$as well as molecules (1) and (2) of $\mathrm{Au}_{4}\left(\mathrm{C}_{2} \mathrm{H}_{4}\right)_{3}{ }^{+}$. Only for molecule (3) of $\mathrm{Au}_{4}\left(\mathrm{C}_{2} \mathrm{H}_{4}\right)_{3}{ }^{+}$back-donation plays a significant role. Thus, $\square \square_{\text {I }}$ and $\square \square_{\text {III }}$ as well as the $\square \square$ parameter represent useful quantities to determine the extent of the $\mathrm{C}=\mathrm{C}$ bond activation (bond length), whereas they do not represent reliable measures for the net charge transfer occurring upon binding of $\mathrm{C}_{2} \mathrm{H}_{4}$ to gold cations.

\section{Conclusions}

In this contribution we have employed IR-MPD spectroscopy in conjunction with density functional theory calculations to reveal the binding configurations of free cationic goldethylene complexes. The comparisons of experimental IRMPD spectra with theoretically obtained vibrational spectra demonstrate that up to three $\mathrm{C}_{2} \mathrm{H}_{4}$ molecules bind to gold cations in a $\square$-bonded configuration while no evidence is found for any appreciable population of di- $\square$-bonded isomers in the molecular beam. The binding is found to be dominated by partial electron donation from the ethylene molecules to the gold clusters leading to an activation of the $\mathrm{C}=\mathrm{C}$ double bond. Charge back-donation is not observed for $\mathrm{Au}_{2}\left(\mathrm{C}_{2} \mathrm{H}_{4}\right)_{\mathrm{y}}{ }^{+}(\mathrm{y}=1,2)$ and $\mathrm{Au}_{3}\left(\mathrm{C}_{2} \mathrm{H}_{4}\right)_{\mathrm{y}}{ }^{+}(\mathrm{y}=2,3)$ while small contributions to the binding are found for $\mathrm{Au}_{3}\left(\mathrm{C}_{2} \mathrm{H}_{4}\right)^{+}$, $\mathrm{Au}_{4}\left(\mathrm{C}_{2} \mathrm{H}_{4}\right)^{+}, \mathrm{Au}_{4}\left(\mathrm{C}_{2} \mathrm{H}_{4}\right)_{2}^{+}$as well as the $\mathrm{C}_{2} \mathrm{H}_{4}$ molecules of $\mathrm{Au}_{4}\left(\mathrm{C}_{2} \mathrm{H}_{4}\right)_{3}{ }^{+}$bound to the twofold coordinated $\mathrm{Au}$ atoms. In contrast, only for a $\mathrm{C}_{2} \mathrm{H}_{4}$ molecule bound to a threefold coordinated $\mathrm{Au}$ atom in $\mathrm{Au}_{4}\left(\mathrm{C}_{2} \mathrm{H}_{4}\right)^{+}$charge back-donation appears to play a non-negligible role. This charge backdonation is caused by the cooperative effect of multiple coadsorbed $\mathrm{C}_{2} \mathrm{H}_{4}$ molecules leading to the accumulation of excess electronic charge on some of the $\mathrm{Au}$ atoms. In all investigated complexes, the gold orbitals mix with $\mathrm{C}-\mathrm{C}$ bond forming orbitals of $\mathrm{C}_{2} \mathrm{H}_{4}$ whereas the $\mathrm{C}-\mathrm{H}$ bond forming orbitals are mainly unaffected. This leads to an activation of the $\mathrm{C}=\mathrm{C}$ double bond while the strong $\mathrm{C}-\mathrm{H}$ bond is not weakened. In agreement, the experimental IR-MPD spectra do not give any indications for $\mathrm{C}-\mathrm{H}$ bond dissociation.

\section{Acknowledgements}

We gratefully acknowledge the Nederlandse Organisatie voor Wetenschappelijk Onderzoek (NWO) for the support of the FELIX Laboratory. The research leading to these results has received funding from LASERLAB-EUROPE (grant agreement no. 654148, European Union's Horizon 2020 research and innovation programme). Computations were carried out at the Georgia Tech Center for Computational Materials Science. B.Y and U. L. were supported by the Air Force Office for Scientific Research (AFOSR) Grant FA9550-15-1-0519. S. M. L. is grateful to the Alexander von Humboldt Foundation for a Feodor-Lynen Scholarship, which, together with the above AFOSR grant, supported S.M.L.'s six month stay at the Georgia Institute of Technology during the work on this study.

\section{References}

[1] Lloyd L, Handbook of Industrial Catalysts, Springer, New York, Dordrecht, Heidelberg, London, 2011.

[2] Farrauto W J, Dorazio L and Bartholomew C H, Introduction to Catalysis and Industrial Catalytic Processes, John Wiley \& Sons, Hoboken, New Jersey, 2016.

[3] Rase H F, Handbook of Commercial Catalysts Heterogeneous Catalysts, CRC Press, Boca Raton, 2000.

[4] Bartholomew C H and Farrauto R J, Fundamentals of Industrial Catalytic Processes, 2nd ed., John Wiley\&Sons, Hoboken, NJ, 2006.

[5] Haruta M, Kobayashi T, Sano H and Yamada N 1987 Chem Lett, 16405.

[6] Hashmi A S K and Hutchings G J 2006 Angew Chem Int Ed, 457896.

[7] Bond G C, Louis C and Thompson D T, Catalysis by Gold, Imperial College Press, London, 2006.

[8] Bond G C and Thomson D T 1999 Catal Rev-Sci Eng, 41 319.

[9] Heiz U and Landman U, Nanocatalysis, in, SpringerVerlag, Berlin, Heidelberg, 2007.

[10] Hutchings G J and Haruta M 2005 Appl Catal A: General, 2912.

[11] Haruta M 2004 Gold Bull, 3727.

[12] Šebera J, Hoffmannová H, Krtil P, Samec Z and Záliš S 2010 Catal Today, 15829.

[13] Lide D R, Handbook of Chemistry and Physics, 76th ed., CRC Press, Boca Raton, FL, 1995.

[14] Outka D A and Madix R J 1987 J Am Chem Soc, 109 1708.

[15] Akemann W and Otto A 1996 Langmuir, 111196.

[16] Ertürk Ü and Otto A 1987 Surf Sci, 179163.

[17] Patterson M L and Weaver M J 1985 J Phys Chem, 89 1331.

[18] Loffreda D 2006 Surf Sci, 6002103.

[19] Torres D and Illas F 2006 J Phys Chem B, 11013310. 
[20] Zinola C F and Luna A M C 1998 J Electronanal Chem, 45637.

[21] Lee C-C and Chen H-T 2015 J Phys Chem A, 119 8547-8555.

[22] Pozun Z D, Tran K, Shi A, Smith R H and Henkelman G 2011 J Phys Chem C, 1151811.

[23] Gammage M D, Stauffer S, Henkelman G, Becker M F, Keto J W and Kovar D 2016 Surf Sci, 65366.

[24] Bus E, Ramaker D E and Bokhoven J A v 2007 J Am Chem Soc, 1298094.

[25] Guzman J and Gates B C 2004 J Catal, 226111.

[26] Lang S M and Bernhardt T M 2012 Phys Chem Chem Phys, 149255.

[27] Böhme D K and Schwarz H 2005 Angew Chem Int Ed, 442336.

[28] Roach P J, Woodward W H, Castleman A W, Jr., Reber A C and Khanna S N 2009 Science, 323492.

[29] Bernhardt T M 2005 Int J Mass Spectrom, 2431.

[30] Lang S M, Popolan D M and Bernhardt T M, Chemical Reactivity and Catalytic Properties of Size-Selected GasPhase Metal Clusters, in: P.D. Woodruff (Ed.) Atomic Clusters: From Gas Phase to Deposited, Elsevier, Amsterdam, 2007, pp. 53.

[31] Lyalin A and Taketsugu T $2010 \mathrm{~J}$ Phys Chem C, 114 2484.

[32] Kang G-J, Chen Z-X and Li Z 2009 J Chem Phys, 131 034710 .

[33] Zhao S Z, Li G Z, Liu J N, Ren Y L, Lu W W and Wang J J 2014 Eur Phys J D, 68254.

[34] Pichugina D A, Lanin S N, Kovaleva N V, Lanina K S, Shestakov A F and Kuzmenko N E 2010 Russ Chem Bul, 59 2039.

[35] Pichugina D A, Nikolaev S A, Mukhamedzyanova D F and Kuzmenko N E 2014 Russ J Phys Chem A, 88959.

[36] Tsipis A C 2010 Organometallics, 29354.

[37] Burratto S K, Bowers M T, Metiu H, Manard M, Tong $\mathrm{X}$, Benz L, Kemper $\mathrm{P}$ and Chretien $\mathrm{S}, \mathrm{Au}_{\mathrm{n}}$ and $\mathrm{Ag}_{\mathrm{n}}(\mathrm{n}=1-8)$ Nanocluster Catalysts: Gas-Phase Reactivity to Deposited Structures, in: D.P. Woodruff (Ed.) Atomic Clusters: From Gas Phase to Deposited, Elsevier, Amsterdam, 2007.

[38] Rupprechter G 2004 Anпu Rep Prog Chem, 100237.

[39] Somorjai G A and McCrea K 2001 App Catal A: General, 2223.

[40] Crampton A S, Rötzer M D, Ridge C J, Schweinberger F F, Heiz U, Yoon B and Landman U 2016 Nat Commun, 7 10389.

[41] Crampton A S, Rötzer M D, Schweinberger F F, Yoon B, Landman U and Heiz U 2016 Angew Chem Int Ed, 55 8953.

[42] McIntosh D and Ozin C A 1976 J Organomet Chem, 121127.

[43] Bakker J M, Lapoutre V J F, Redlich B, Oomens J, Sartakov B G, Fielicke A, von Helden G, Meijer G and van der Meer A F G 2010 J Chem Phys, 132074305.

[44] Haertelt M, Lapoutre V J F, Bakker J M, Redlich B, Harding D J, Fielicke A and Meijer G 2011 J Phys Chem Lett, 21720.
[45] Oomens J, Sartakov B G, Meijer G and Helden G v 2006 Int J Mass Spectrom, 2541.

[46] Kresse G and Hafner J 1993 Phys Rev B, 47558.

[47] Kresse G and Hafner J 1994 Phys Rev B, 4914251.

[48] Kresse G and Furthmüller J 1996 Phys Rev B, 5411169.

[49] Kresse G and Furthmüller J 1996 Comp Mat Sci, 615.

[50] Kresse G and Joubert D 1999 Phys Rev B, 591758.

[51] Perdew J P, Burke K and Ernzerhof M 1996 Phys Rev

Lett, 773865.

[52] Makov G and Payne M C 1995 Phys Rev B, 514014.

[53] Cordero B, Gómez V, Platero-Prats A E, Revés M, Echeverría J, Cremades E, Barragán F and Alvarez S 2008 Dalton Trans, 2832.

[54] Giannozzi P and Baroni S 1994 J Chem Phys, 1008537. [55] Baroni S, de Gironcoli S, Dal Corso A and Giannozzi P 2001 Rev Mod Phys, 73515.

[56] Rivalta I, Mazzone G, Russo N and Sicilia E $2009 \mathrm{~J}$ Chem Theo Comp, 51350.

[57] Shimanouchi T, Tables of Molecular Vibrational Frequencies Consolidated Volume I, National Bureau of Standards, 1972.

[58] Lang S M, Bernhardt T M, Chernyy V, Bakker J M, Barnett R N and Landman U 2017 Angew Chem Int Ed, 56 13406

[59] Lang S M, Bernhardt T M, Barnett R N and Landman U 2010 Chem Phys Chem 111570.

[60] Stuve E M and Madix R J 1985 J Phys Chem, 893183. 